OPEN ACCESS

Edited by:

Goetz Hensel,

Leibniz Institute of Plant Genetics

and Crop Plant Research (IPK),

Germany

Reviewed by:

Steven Footitt,

Boğaziçi University, Turkey

Ning Zhang,

Gansu Agricultural University, China

Sepideh Anvarkhah,

Ferdowsi University of Mashhad, Iran

*Correspondence:

Xuebo Hu

xuebohu@mail.hzau.edu.cn

Specialty section:

This article was submitted to

Plant Biotechnology,

a section of the journal

Frontiers in Plant Science

Received: 11 January 2020

Accepted: 15 May 2020

Published: 24 June 2020

Citation:

Juneidi S, Gao Z, Yin $\mathrm{H}$,

Makunga NP, Chen W, Hu S, Li X and

HuX (2020) Breaking the Summer

Dormancy of Pinellia ternata by

Introducing a Heat Tolerance

Receptor-Like Kinase ERECTA Gene.

Front. Plant Sci. 11:780.

doi: 10.3389/fpls.2020.00780

\section{Breaking the Summer Dormancy of Pinellia ternata by Introducing a Heat Tolerance Receptor-Like Kinase ERECTA Gene}

\author{
Seifu Juneidi1,2,3, Zengyan Gao ${ }^{1,2,3}$, Huanran Yin ${ }^{4}$, Nokwanda P. Makunga ${ }^{5}$, Wei Chen ${ }^{4}$, \\ Sheng $\mathrm{Hu}^{6}$, Xiaohua $\mathrm{Li}^{1,2,3}$ and Xuebo $\mathrm{Hu}^{1,2,3 *}$ \\ 1 Laboratory of Drug Discovery and Molecular Engineering, Department of Medicinal Plants, College of Plant Science \\ and Technology, Huazhong Agricultural University, Wuhan, China, ${ }^{2}$ National-Regional Joint Engineering Research Center \\ in Hubei for Medicinal Plant Breeding and Cultivation, Huazhong Agricultural University, Wuhan, China, ${ }^{3}$ Medicinal Plant \\ Engineering Research Center of Hubei Province, Huazhong Agricultural University, Wuhan, China, ${ }^{4}$ National Key Laboratory \\ of Crop Genetic Improvement and National Center of Plant Gene Research (Wuhan), Huazhong Agricultural University, \\ Wuhan, China, ${ }^{5}$ Department of Botany and Zoology, Stellenbosch University, Stellenbosch, South Africa, ${ }^{6}$ Hubei Cancer \\ Hospital, Wuhan, China
}

Pinellia ternata is a perennial traditional Chinese medicinal plant that undergoes different phenological patterns of dormancy depending on where it is growing. Plants grown in central and southern China typically display two growth cycles every year before and after hot summer days, exhibiting a summer dormancy. However, germplasms from these areas do not go into a dormancy phase in northern China where the summer monthly average temperatures range from $29-31^{\circ} \mathrm{C}$. The northern China herbal growers prefer plant stocks from central China due to their longer growing quality and better tuber harvests. Here, we introduced a heat responsive receptor-like kinase ERECTA (ER) gene into $P$. ternata to explore changes in the growth cycle which were aimed at disrupting the summer dormancy. The 3-hydroxy-3-methylg/utaryl coenzyme A reductase (HMGR) gene was also co-transformed with ER to improve the commercial trait. For the thermo-tolerance evaluation, all plants were treated with high temperatures $\left(35^{\circ} \mathrm{C} / 40^{\circ} \mathrm{C}\right)$ in a growth chamber or grown in natural field temperature in an isolated field before measurement of different agricultural, biochemical and physiological traits. The transgenics showed significantly $(P<0.05)$ higher heat tolerance, maintaining healthy vegetative growth unlike the empty vector $(E V)$ harboring controls that became chlorotic and necrotic. Better performance in some of the monitored physiological traits was evident for overexpression lines exposed to the heat stress. In open isolated field trials, the transgenic genotypes did not show a summer dormancy but had a survival rate of $84-95 \%$. The tuber biomasses were also significantly $(P<0.05)$ higher for the transgenic lines as compared to the EV controls, except for line ER118. Metabolites analysis indicated that the HMGR overexpressing lines (HMGR orHMGR + ER) exhibited significantly higher amounts of bioactive compounds including aromadendrene-4, 10-diol and 4, 8, 13-cyclotetradecatriene-1, 3-diol, 1, 


\begin{abstract}
5, 9-trimethyl-12-(1-methylethyl). Our findings show that the summer dormancy of $P$. ternata which is a naturally evolved trait, can be removed by a single heat responsive gene. The study contributes to generating heat tolerant new Pinellia varieties with enhanced commercially valuable chemicals.
\end{abstract}

Keywords: ER, HMGR, Pinellia ternata, secondary metabolites, summer-dormancy, thermo-tolerance

\section{INTRODUCTION}

Pinellia ternata (Thunb) Breit (Araceae) is a perennial plant that normally grows in humid and shady environments with moderate temperatures ( $\mathrm{Hu}, 1989)$. It is native to Eastern Asian countries, namely; Korea, Japan and China. In China, Pinellia is cultivated mainly in the central and southwest provinces (Zhang et al., 2013) because it is an important medicinal plant. Some plants have evolved a dormancy mechanism during winter or summer as an adaptation to cope with drought or heat stresses (Gillespie and Volaire, 2017). P. ternata is naturally susceptible to high temperatures in the summer season and its aerial parts start to wither and senesce from mid-July when it slows down its normal vegetative growth. In central and southern China, where the summer temperatures can reach above $35^{\circ} \mathrm{C}$, the plant undergoes seasonal dormancy. However, in northern China, where the summer temperatures are relatively lower than in central China, the Pinellia plant grows continuously without showing a seasonal summer dormancy. Herbal growers generally prefer genotypes of this species that originate from central China because they have a better yield (Ma et al., 2006; Zhang et al., 2013). Strategies that alter the phenology of these genotypes, which circumvent the heat response that induces summer dormancy, are thus highly desirable.

Recently, much progress has also been made in improving plant tolerance to heat stress through genetic modifications. One of these strategies includes overexpressing the ERECTA gene of the family Leucine-Rich Repeat Receptor-Like Protein Kinases (LRR-RLKs) into Arabidopsis and economically important crops. Members of the $L R R-R L K$ gene family have been shown to improve the ability of plants to tolerate heat when plants are challenged with high temperature stress for a long duration (Shpak et al., 2004; Shen et al., 2015). In Arabidopsis, the ER gene family is composed of ERECTA, ERECTA-LIKE1 and ERECTA-LIKE2. These genes are known to regulate multiple aspects of plant development including proximodistal axis elongation, anther differentiation, integument growth promotion, xylem radial expansion and vascular bundle differentiation (Shpak, 2013).

$P$. ternata is one of the most popular herbal medicines that used for the treatment of insomnia, tumor, eclampsia, obesity and depression for hundreds of years in Chinese Traditional Medicine (Iwasa et al., 2014). Its tubers are the main source of bioactive phytochemicals that show antitussive, antioxidant, antibacterial, anti-inflammatory and antiemetic actions (Hongying et al., 2015). Several specialized metabolites have been identified in this species including terpenoids, lignanoids, alkaloids, and phenylpropanoids (Wu et al., 2011; Iwasa et al., 2014). Some of these accumulate at low levels (Zuo et al., 2012;
Lee et al., 2016) and the application of transgenic technologies can offer solutions to generate Pinellia cultivar(s) with improved chemical, agricultural and/or commercial traits.

In spite of this, genetic modifications in this species are few. As example, Tang et al. (2008) introduced the aroA-M12 glyphosate resistance gene and Jin et al. (2009) generated fungal resistant P. ternata expressing the chitinase gene (ech42) and $\beta-1,3$ glucanase gene (gluc78). Zhu et al. (2018) transformed with the sHSP genes that encode for small heat shock proteins. However, none of these studies directly focused on specialized metabolism. To our knowledge there are no reports available with regard to genetic modifications of the HMGR gene, a rate limiting enzymes, to improve the production of specialized metabolites of $P$. ternata. The HMGR gene encodes an enzyme that is crucial in the biosynthesis of terpenoids and alkaloids (Bansal et al., 2018). We, thus, hypothesized that the overexpression of HMGR could enhance the secondary metabolite content and provide new evidence for its regulatory function in heat stress tolerance.

The aims of this study were two fold. Initially, we explored how a heterologous Arabidopsis ER gene would change the basic life cycle of $P$. ternata as our target was to break the heat-inducible summer dormancy pattern (Figure 1). The study also examined the role of the HMGR gene in regulating heat tolerance in $P$. ternata. In other taxa, the HMGR enzyme responds to various biotic and abiotic stresses, leading to altered metabolite profiles. To the best of our knowledge, this is the first report to break plant summer dormancy by overexpressing a heat responsive gene concomitant to improving the chemo-type of Pinellia via HMGR up-regulation of specialized metabolism.

\section{MATERIALS AND METHODS}

\section{Construction of Expression Vectors}

The cDNA clone of ER in PCAMBIA1301 expression vector was obtained from Professor He Zuhua, Shanghai Institute of Life Sciences (Chinese Academy of Sciences, China). The heat stress response of the ER gene was previously described by Shen et al. (2015). The plasmid was extracted using a Kang Ji Century extraction kit before it was analyzed using 1\% (w/v) agarose gel electrophoresis. A nanodrop2000 spectrophotometer was used throughout the study to quantify nucleic acids (Thermo Fisher Scientific, United States).

The PESC-HIS-mvaA vector harboring the HMGR gene was a generous gift from Professor Zhang Yansheng [Wuhan Botanical Garden (Chinese Academy of Sciences, China)]. The gene was excised from the vector using restriction digestion with Ncol and BstEII restriction enzymes before $10 \mu \mathrm{g}$ of the digestion 
was applied to a $1 \%(\mathrm{w} / \mathrm{v})$ agarose/ethidium bromide gel. The cut gel fragment was purified using Kanto's PCR gel clean up kit. Two different constructs were made i.e., CaMV35:HMGR or CaMV35:HMGR + CaMV35:ER. These were inserted into the $P C A M B I A 1301-E R$ vector, containing the ER gene. A gene construct, the CaMV35S:HMGR + CaMV35S:ER was generated using a ligation reaction with a ratio of $3: 1$ ratio $(\mathrm{v} / \mathrm{v})$ regarding the HMGR fragments to $P C A M B I A 1301-E R$ vector. The gene construct was transformed into $\mathrm{DH} 5 \alpha$ competent cells using a
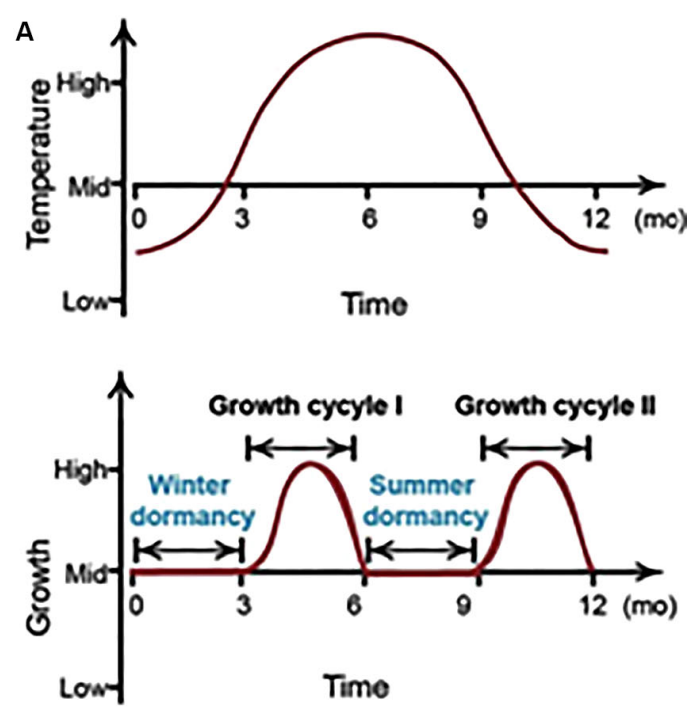

B
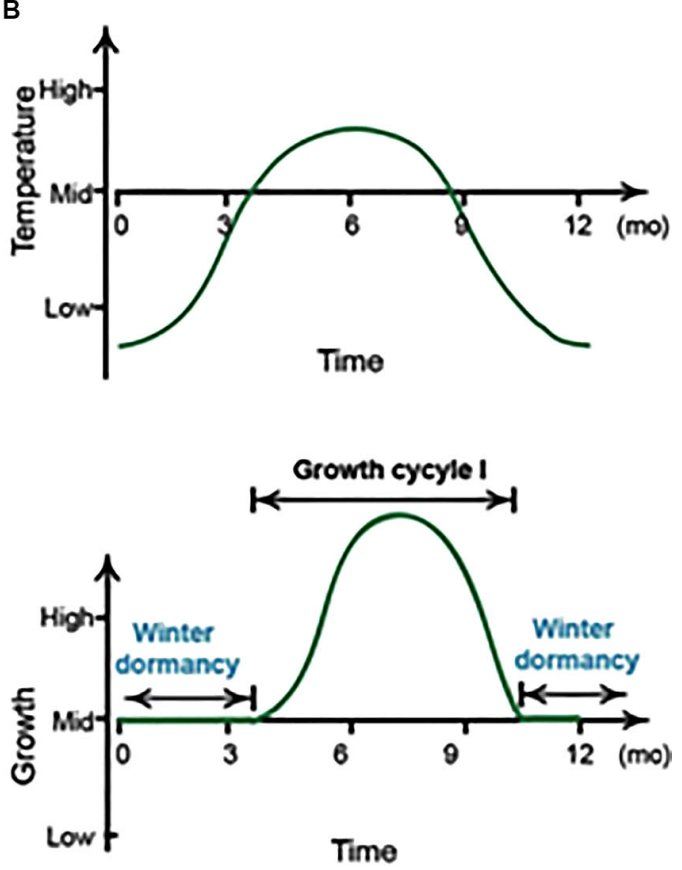

FIGURE 1 | A depiction of $P$. ternata growth cycles. In southern and central China, $P$. ternata develops two seasonal dormancy periods every year (A), whereas it has one dormancy period per year in northern China (B). mo, month. heat shock method (Froger and Hall, 2007). The transformants were then grown on Luria Bertoni selective medium $\left(50 \mathrm{mg} \mathrm{L}^{-1}\right.$ kanamycin), and the positive clones were screened using a colony PCR. The correct recombinant orientation of the insert to the vector was verified by sequencing. Five hundred nano gram of plasmid DNA was used as a template for sequencing, and a sequencing comparison was made electronically via BLAST of National Centre for Biotechnology Information (NCBI).

\section{Agrobacterium Transformation}

The CaMV35:HMGR or CaMV35:HMGR + CaMV35:ER constructs were cloned into the $P C A M B I A 1301$ expression vector, and then transformed into Agrobacterium via electroporation (Yang et al., 2000). The transformants were diluted in $1 \mathrm{ml}$ antibiotic-free yeast extract peptone (YEP) medium and incubated for $1 \mathrm{~h}$. The cells were recovered by centrifugation at 3,500 $\mathrm{g}$ for $5 \mathrm{~min}$. The collected cells were then grown on a YEP selective medium containing $50 \mathrm{mg} \mathrm{L}^{-1}$ rifampicin and $50 \mathrm{mg} \mathrm{L}^{-1}$ kanamycin for 2 days at $28^{\circ} \mathrm{C}$. Colony PCR was used to verify positive clones.

\section{Explant Preparation, Growth Condition and Plant Transformation}

Healthy $P$. ternata tubers were collected from the Dong Yanni Pinellia co-operatives production site $\left(30^{\circ} 24^{\prime} \mathrm{N} 112^{\circ} 54^{\prime} \mathrm{E}\right)$, Qianjiang, Hubei, China. The plant species was identified by Professor Hu Xuebo, Department of Medicinal Plants, Huazhong Agricultural University (HZAU), China. The surfaces of tubers were disinfected with $75 \%(\mathrm{v} / \mathrm{v})$ ethanol for $10 \mathrm{~min}$, followed by soaking in $0.1 \% \mathrm{HgCl}_{2}(\mathrm{w} / \mathrm{v})$ for $20 \mathrm{~min}$. Decontaminated tubers were then grown on Murashige and Skoog (1962) basal medium to generate in vitro stock plants. The plant growth chamber conditions were set at $25 \pm 2{ }^{\circ} \mathrm{C}$ temperature, 3,000 Lux light intensity, 16/8 h light/dark photoperiod and $\sim 65 \%$ relative humidity. Leaf discs $(1-1.5 \mathrm{~cm})$, excised from 5 week-old plantlets, were placed together with an Agrobacterium suspension culture, harboring the transgenes, for $15 \mathrm{~min}$. After infection, the plant material was transferred to co-cultivation MS medium containing $100 \mu \mathrm{g} \mathrm{L}^{-1}$ acetosyringone and kept in dark area for $72 \mathrm{~h}$ at $25^{\circ} \mathrm{C}$ as previously described by $\mathrm{Xu}$ et al. (2005). Three days later, the plant material was thoroughly washed with sterile water, blotted dry with Whatman No.1 filter papers and transferred to MS solid medium to generate transgenic plants. Shoot regeneration was induced on a selection MS medium containing $30 \mathrm{~g} \mathrm{~L}^{-1}$ sucrose, $1 \mathrm{mg} \mathrm{L}^{-1}$ Kinetin (KT), $30 \mathrm{mg} \mathrm{L}^{-1}$ hygromycin, $50 \mathrm{mg} \mathrm{L}^{-1}$ kanamycin and $50 \mathrm{mg}$ $\mathrm{L}^{-1}$ rifampicin. After 5 weeks, the shoots were transferred to a root inducing MS medium supplemented with $30 \mathrm{~g} \mathrm{~L}^{-1}$ sucrose, $1 \mathrm{mg} \mathrm{L}^{-1} \mathrm{KT}, 0.1 \mathrm{mg} \mathrm{L}^{-1}$ 2, 4-dichlorophenoxyacetic acid (2, 4-D), $0.1 \mathrm{mg} \mathrm{L}^{-1} 1$-naphthalane acetic acid (NAA), $30 \mathrm{mg} \mathrm{L}^{-1}$ hygromycin, $50 \mathrm{mg} \mathrm{L}^{-1}$ kanamycin and $50 \mathrm{mg} \mathrm{L}^{-1}$ rifampicin. The positive transformants were then verified by using PCR.

For each genetic construct (CaMV35:HMGR, CaMV35:ER or CaMV35:HMGR + CaMV35:ER), twenty individual transgenic plant lines were produced. Ten transgenic lines of each construct that looked morphologically similar to untransformed plants 
were selected. Transgene expression levels were also used for selection of transgenic lines using RT-PCR (see description in the next section). A preliminarily heat resistance screening test, where, transgenic plants were subjected to a $40^{\circ} \mathrm{C}$ heat treatment for 7 days was also used. Apart from higher temperature, all other conditions in the growth chamber were kept same, as previously mentioned. The best three thermo-tolerant lines of each construct were selected for further studies. The empty vector (hereafter denoted as $E V$ ) harboring plants were used as controls.

\section{Real-Time PCR}

Total RNA was isolated from leaves of 10 -week-old Pinellia plantlets using CTAB-pBIOZOL reagents according to the manufacturer's instructions (BIOER). The RNA was treated with an RNase-free DNase before cDNA was generated from $1 \mu \mathrm{g}$ of total RNA using a SuperReal PreMix Plus (SYBR Green) TIANGEN kit. Two microliters of cDNA were used for qPCR analysis with SYBR Green PCR master mix using the aqTOWER 2.2 real- time PCR detection systems (Analytikjena, Jene, Germany). The total volume of the reaction was adjusted to $20 \mu \mathrm{L}$. The primer sequences used are in Supplementary Table S1. Three biological replicates were used for gene expression analysis. The $2^{-\Delta} \Delta C t$ method (Livak, 2001) was used to quantify the relative expression levels of $H M G R, E R$ and $H M G R+E R$ (hereafter denoted as $H+E$ ). The Actin gene was used as a housekeeping control.

\section{Heat Treatment Response of ER Overexpressing Pinellia}

\section{Plant Growth and Morphological Characterization}

The selected three transgenic lines of each $E R$ or $H+E$, and the $E V$ control plantlets were grown on MS medium in a growth chamber for 8 weeks as mentioned earlier. Plantlets were transplanted into soil and grown in a growth culture room that had similar growth conditions with the growth chamber. After 2 weeks, the seedlings were subjected to different temperatures, namely high temperature treatment $\left(40^{\circ} \mathrm{C}, 15\right.$ day) or a long-term warm temperature regime $\left(35^{\circ} \mathrm{C}, 90\right.$ day) plus natural field temperature in a pot trial in an isolated field. High and long-term temperature treatments were adopted from the method of Shen et al. (2015) with slight modifications. Briefly, 10 -week-old seedlings were grown at $40^{\circ} \mathrm{C}$ (heat stress) for 15-day followed by a 15-day recovery growth period at $25^{\circ} \mathrm{C}$ (normal growth temperature)-to determine high temperature stress survival and recovering rates. Likewise, 10 -week-old seedlings were grown at $35^{\circ} \mathrm{C}$ for 90 -day for a prolonged warm temperature stress survival rate assessment. The heat survival rate was defined as the ratio of the number of plants maintaining green shoots to the total number of plants that were subjected to the stress temperatures. The ability to survive these temperature regimes was recorded daily. Changes in plant morphology were monitored and recorded daily. Plants were watered manually every other day to maintain soil moisture during the heat treatments. The rate of recovery was also monitored for the plants that were treated with a high temperature at $40^{\circ} \mathrm{C}$. The recovery rate was described as the ratio of the number of plants that exhibited normal development when growing at the normal growth temperature at $25 \pm 2{ }^{\circ} \mathrm{C}$.

\section{Physiological Response Measurements}

In situ leaf chlorophyll content was measured before and during heat stress treatments at $0,24,48$, and $72 \mathrm{~h}$ using a SPAD 502 plus chlorophyll meter (Konica Minolta, Japan). Briefly, 5-10 fully expanded intact, clean and healthy leaves were selected and measured for relative in situ chlorophyll content. A single leaf was measured at least five times and an average of the measurements was considered as the representative of leaf chlorophyll content. The net photosynthetic rate, transpiration rate, internal $\mathrm{CO}_{2}$ concentration and stomatal conductance of 10-week-old plantlets were measured using a LI-COR6400 (LI-COR Biosciences, United States) gas exchange system according to Shen et al. (2015). A batch of 15-25 plants was measured before $(0 \mathrm{~h})$ and after a $48 \mathrm{~h}$ heat treatment using three biological replicates. The instantaneous water-use efficiency was determined from the ratio of the net photosynthetic rate to transpiration rate, and the relative water content was measured according to Xu et al. (2014).

\section{Oxidative Stress Damage Analysis}

Different measurements linked to ion leakage, $\mathrm{H}_{2} \mathrm{O}_{2}$ and $\mathrm{O}_{2}{ }^{-}$detection, lipid peroxidation, total protein content and superoxide dismutase (SOD) activity were recorded. Leaves of 10-week-old Pinellia were used for the detection of ion leakage (Zang et al., 2017). Total protein content was measured spectrophotometrically using Bradford protein assay method (Krohn, 2001). The $\mathrm{H}_{2} \mathrm{O}_{2}$ tests (Alexieva et al., 2001) and leaf lipid peroxidation malonaldehyde (MDA) assay (Shiu et al., 2004) was conducted. The activity of SOD was measured similarly to Beauchamp and Fridovich (1971). The histochemical staining of detached leaves that were infiltrated with 3, 3'-diaminobenzidin $(\mathrm{DAB})$ or nitrotetrazolium blue chloride (NBT)were evaluated for the accumulation of $\mathrm{H}_{2} \mathrm{O}_{2}$ or superoxide radical anions $\left(\mathrm{O}_{2}{ }^{-}\right)$, respectively (Kumar et al., 2014).

\section{Open Field Trials}

Field tests were conducted in 2018 and 2019 at the HZAU experimental station, Wuhan, China. The ER overexpressing plantlets were grown on MS medium for 8 weeks before being transferred to soil and acclimatized ex vitro for 2 weeks in a growth culture room. In each experiment the plants were grown in pots $(9 \mathrm{~cm}$ height $\times 10.16 \mathrm{~cm}$ width) containing a soil mix of perlite: humus (1:1). Ten-week-old Pinellia microplants were then transplanted to an experimental site during the spring (April-June) and the summer (July-September) seasons for an open natural field experiment. Daily records of relative humidity and temperatures (low, high, and average) were obtained from the Wuhan meteorological service station (Supplementary Table S4). Thirty to forty plants of each individual line in a randomized designed were grown and analyzed for different agronomic traits including plant height, root length, total plant biomass, survival rates, and tuber biomass. The agronomic 
traits records were collected in spring (April-June) and summer (June-September) seasons for a seasonal comparison in terms of temperature differences.

\section{Extraction of Metabolites}

Each tuber was cut into sections and then dried at room temperature, for 2 days, before the material was ground to a fine powder using a pestle and mortar. The powder was extracted in methanol (1:5 ratio; $\mathrm{w} / \mathrm{v})$ for $1 \mathrm{~h}$. The homogenate was then sonicated at $60^{\circ} \mathrm{C}$ for $110 \mathrm{~min}$ using an ultra-sonicator bath (Rico Scientific Industries, India). The extract was filtered using Whatman No. 1 and cellulose membrane filter paper and afterward the organic solvent was evaporated to dryness using a RV 3 V-C rotary evaporator (IKA, United States). Each residue was dissolved in $5 \mathrm{ml}$ methanol before gas chromatography mass spectrometry (GC-MS).

\section{Analysis of Metabolites by GC-MS}

The GC-MS analysis was conducted using a Shimadzu GC-MSTQ8040 system (Kyoto, Japan) coupled directly to a MS detector. The chromatographic separation was performed using the Rtx5MS (5\% phenyl-95\% polydimethyl siloxane; $30 \mathrm{~m} \times 0.25 \mathrm{~mm}$ ID, $0.25 \mu \mathrm{m}$ ) fused-silica column supplied by Restek (Bellefonte, United States). Helium was used as carrier gas at a constant flow rate of $1 \mathrm{~L} \mathrm{~min}-1$. The ion source and interface temperatures were set at 230 and $290^{\circ} \mathrm{C}$, respectively. Sample injection used a split mode (ratio 10:1) and the injector port temperature was set to $280^{\circ} \mathrm{C}$ whilst the GC oven temperature program was set as follows: $80^{\circ} \mathrm{C}$ ( $3 \mathrm{~min}$ hold), ramped to $110^{\circ} \mathrm{C}(5 \mathrm{~min}$ hold $)$ at $10^{\circ} \mathrm{C} \mathrm{min}^{-1}$, increased to $190^{\circ} \mathrm{C}$ ( 3 min hold), ramped to $220^{\circ} \mathrm{C}(4 \mathrm{~min}$ hold $)$ at $10^{\circ} \mathrm{C} \mathrm{min}^{-1}$, and then increased to $280^{\circ} \mathrm{C}$ (13 min hold) at $15^{\circ} \mathrm{C} \mathrm{min}^{-1}$. The MS detector, operated at $70 \mathrm{eV}$, was set to scan from 60 to 665 atomic mass units. The compounds were identified by comparing spectra of the analyzed samples with the National Institute of Standards and Technology (NIST) library, 2008 and Wiley Registry of Mass Spectral Data, 8th Edition. High match scores (>95\%) were considered for compound identification (Lee et al., 2016) and where possible this was checked with published literature.

\section{Statistical Analysis}

One-way ANOVA was used for data analysis, and the significant differences between the control and the transgenic plants were using a Fisher's Least Significant Difference (LSD) test $(P<0.05)$. Applications were conducted with the SPSS statistical program (version 23).

\section{RESULTS}

\section{Gene Expression and Transgenic Plant Screening}

The ER, HMGR and HMGR + ER genes were constitutively overexpressed in $P$. ternata under the transcriptional control of CaMV35S promoter to gain insight into their functions. In total, 20 transgenic lines of each genotype were produced.
The transcript levels were significantly $(P<0.05)$ increased in all transgenic plants and hardly detected in the EV controls (Supplementary Figure S1). To test the functionality of these genes, the transgenic plants were subjected to high temperature $\left(40^{\circ} \mathrm{C}, 7\right.$-day) as part of preliminary screening for thermotolerance. Together with the qRT-PCR analysis, three best heat tolerant lines of each group (ER: 115,118,122; $H+E: 58,100,182)$ were selected (Figures $\mathbf{2 A}-\mathbf{C}$ ) and used to continue the study. Under heat stress, the HMGR transgenic lines were similar in their morphological appearance to the control plants with the empty vector (refer Supplementary Tables S2, S3 for recorded phenotypic traits).

\section{Overexpression of ER Confers Thermo-Tolerance of $P$. ternata}

Temperature stress suppressed the growth of both the transgenic $E R$ overexpression (ER-OE) and the $E V$ controls when plants were exposed to a temperature of $40^{\circ} \mathrm{C}$ for 15 days. However, the stress effect was more severe in the $E V$ controls than the transgenic genotypes (Figures 2D-H). Under normal growth temperatures, there were no obvious differences in plant growth, morphology or biomass as compared to the $E V$ controls. But, under heat stress, a different scenario was noticed where the $E V$ controls rapidly wilted, showing signs of leaf necrosis and chlorosis. The EV controls also exhibited stunted growth and distortion of leaf shape, reduced leaf size and drying of leaf veins whereas the leaves of the transgenic lines remained relatively green and healthy with minor apparent morphological deformities.

We measured chlorophyll content of the intact leaves to test the effect of ER-OE in alleviating high temperature stress and/or its possible role in reducing chlorophyll damage. The plantlets regenerated initially at $25 \pm 2^{\circ} \mathrm{C}$ were transferred to the high temperature treatment of $40^{\circ} \mathrm{C}$, and the leaves were sampled at different time points $(0,24,48$, and $72 \mathrm{~h})$ for in situ chlorophyll content. No differences were observed between the $E V$ controls and the transgenic plants when plants were grown at $25 \pm 2{ }^{\circ} \mathrm{C}$. The chlorophyll content ranged from $42.1 \pm 1.3$ to $46.5 \pm 0.9 \mathrm{mg} \mathrm{cm}^{-1}$. The chlorophyll content was significantly lowered when plants were exposed to heat stress irrespective of their transgenic status but the effect was more pronounced for the $E V$ controls at each sampled time point. After $72 \mathrm{~h}$, the highest and the lowest chlorophyll contents were measured for the ER122 $\left(24.6 \pm 0.8 \mathrm{mg} \mathrm{cm}^{-1}\right)$ and the $E V$ controls $\left(16.5 \pm 1.2 \mathrm{mg} \mathrm{cm}^{-1}\right)$, respectively (Figure 2D).

Under heat stress, the stress tolerance of all the genotypes showed a decline over the 15-day of treatment and this result were statistically significant. Despite this, the heat stress resistance was remarkably higher for the transgenic genotypes than the $E V$ controls at each tested time point. On the 15th day, the highest tolerance was recorded for the ER122 line (26.5\%) followed by the ER118 (24.8\%) and $H+E 100$ (23.7\%) transgenic genotypes. As expected the $E V$ controls had the lowest tolerance as only $12.4 \%$ of $E V$ controls survived high temperature treatment on day 15. The rate of recovery can indicate how detrimental elevated temperatures are to plants and for the transgenic genotypes, 

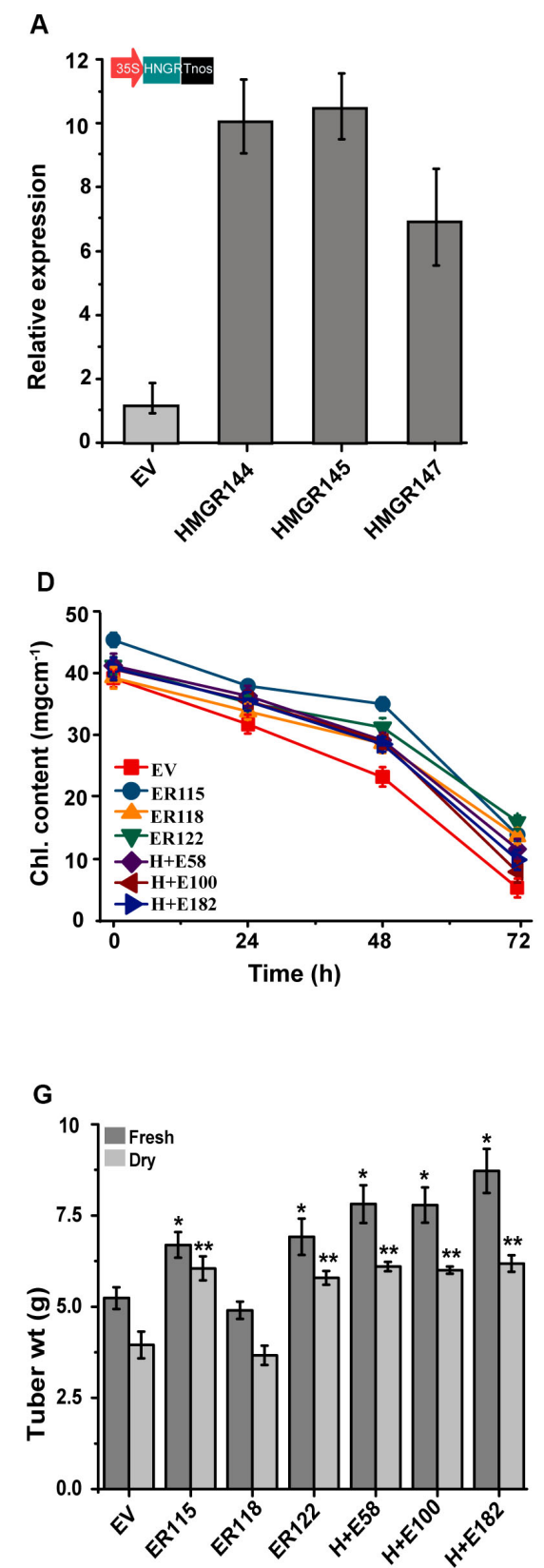

B

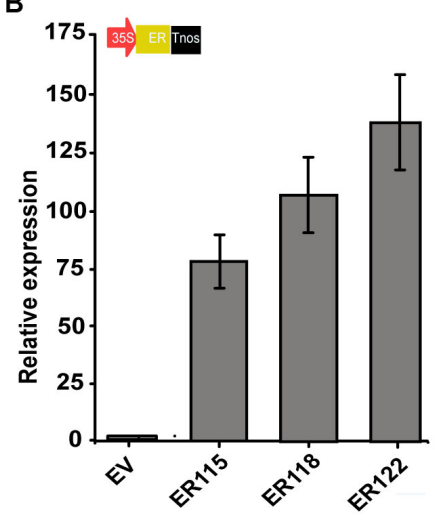

E

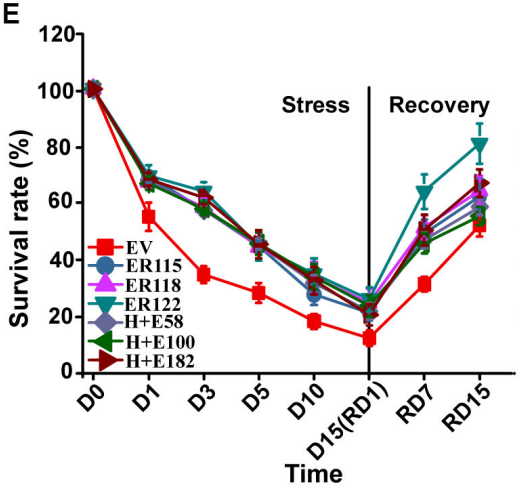

$\mathbf{F}$

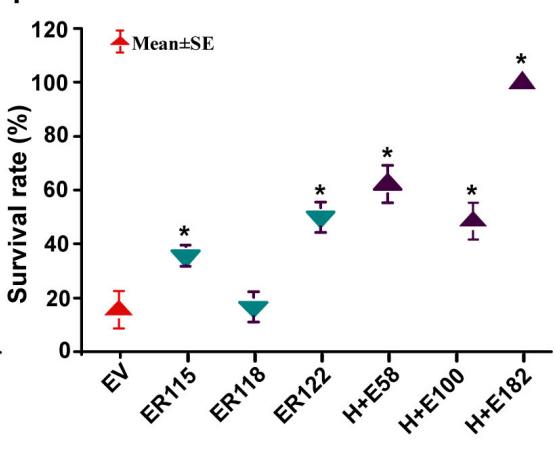

H

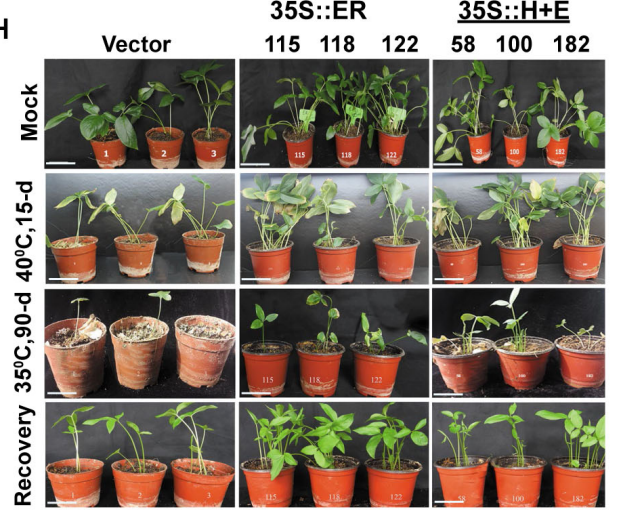

FIGURE 2 | ER enhances thermo-tolerance of $P$. ternata. The relative expression levels of (A) HMGR, (B) ER and (C) H + E in 10-week-old $P$. ternate overexpressing HMGR, ER or $H+E$ under the control of CaMV35S promoter. The Actin gene was used as a control to normalize internal expression level. (D) SPAD leaf chlorophyll content of the empty vector, $E R$ and $H+E$ genotypes sampled at $0,24,48$, and $72 \mathrm{~h}$. (E) Heat stress survival rate of the empty vector, $E R$ and $H+E$ genotypes subjected to a high temperature $\left(40^{\circ} \mathrm{C}, 15\right.$-day) and their recovery at a normal growth temperature $\left(25 \pm 2{ }^{\circ} \mathrm{C}, 15\right.$-day). (F) Long-term warm temperature survival rate $\left(35^{\circ} \mathrm{C}, 90\right.$-day). (G) Tuber weights of the transgenic Pinellia plants grown in a growth chamber at $35^{\circ} \mathrm{C}, 90$-day and recovered under normal growth temperature ( $25 \pm 2^{\circ} \mathrm{C}, 9$ months), 9-12 plants each. (H) Phenotype of 10-week-old transgenic $P$. terneta grown at $25 \pm 2^{\circ} \mathrm{C}$ (the first upper panels) and subsequently grown for 15 -day at $40^{\circ} \mathrm{C}$ (the second middle panels), followed by 15 -day growth recovery at $25 \pm 2^{\circ} \mathrm{C}$ (the fourth lowest panels) and plants grown for 90 -day at $35^{\circ} \mathrm{C}$ (the third middle panels). Scale bar $1 \mathrm{~cm}$. $P<0.05$, by one-way ANOVA, LSD for comparisons; Chl., chlorophyll; D, day; RD, recovery day.

the recovery rate was significantly higher at each sampled time point versus the $E V$ controls. Out of the transgenic lines, the $E R 122$ and the $E V$ genotypes had the best revival rates of $80.7 \%$ and the lowest $52 \%$ at termination of the experiment, respectively. During the course of the prolonged moderate heat treatment $\left(35^{\circ} \mathrm{C}, 90\right.$-day $)$, the leaves of the $E V$ controls turned to a yellow, wilted and eventually died. On the other hand, the leaves of the transgenic lines remained green; sustaining their growth and development much better as compared to the $E V$ controls (Figures 2E,F,H). 


\section{ER Overexpression Alters the Physiological Responses of $P$. ternata Against Heat Stress}

To assess the physiological responses of ER-OE P. ternata, the net photosynthetic rate, transpiration rate, internal $\mathrm{CO}_{2}$ concentration, stomatal conductance, instantaneous water-use efficiency and relative water content were measured before $(0 \mathrm{~h})$ and after $(48 \mathrm{~h})$ the heat stress treatment (Figures 3A-F). Except for the $H+E 58$ and $H+E 100$ lines, no differences in net photosynthetic rate measurements were observed between the transgenic and the $E V$ controls at $25 \pm 2{ }^{\circ} \mathrm{C}$. With elevated temperature of $40^{\circ} \mathrm{C}$, differences were observed between the transgenic and the $E V$ controls. Photosynthetic rates were significantly higher in the transgenic lines as compared to the $E V$ controls (Figure 3A). Apart from the ER115 (under normal and stress conditions) and the ER118 lines (under the heat stress condition), there was no significant difference in transpiration rate between the transgenic and the $E V$ controls (Figure 3B). With regards to the intercellular $\mathrm{CO}_{2}$ content, the differences between the transgenic and the $E V$ controls were not significant at the normal growth temperature, except for the ER122 line. The internal $\mathrm{CO}_{2}$ concentration content was significantly increased when plants were exposed to different heat stressing regimes in all genotypes but the variation was substantial for the $E V$ controls (Figure 3C).

The instantaneous water-use efficiency describes the ratio of the net photosynthetic rate to transpiration rate, and changes in either of the two components causes variation in instantaneous water-use efficiency of a plant. Essentially, both parameters are often driven by the plant's stomatal conductance. For this reason, we measured the stomatal conductance before and after heat treatments. The ER-OE genotypes were characterized by much higher leaf stomatal conductance than the $E V$ controls with exposure to high heat (Figure 3D). The transgenic lines exhibited significantly higher instantaneous water-use efficiency than the $E V$ controls under the heat treatment (Figure 3E). The data shows that the transgenic plants maintained a significantly higher rate of carbon assimilation (2.75-4.13 folds) as compared to the $E V$ controls when under heat stress. Leaf rolling became a morphological feature that was associated with plants under heat stress and this was more prominent the longer the period of stress. As a result, we were unable to properly measure the physiological responses of plants from this point onward. The relative water content of the excised plant leaves, which were measured over the time points of 0,24 , and $48 \mathrm{~h}$, were statistically insignificant under normal growth temperatures. After $24 \mathrm{~h}$ of heat exposure, however, the relative water content of the $E V$ controls declined more rapidly from 94.8 to $87.1 \%$. Values of $10.4 \%$ for the $E V$ controls and $4.1-7.2 \%$ for the transgenic lines were recorded at the end of the $48 \mathrm{~h}$ heat stress treatment (Figure 3F).

\section{ER Reduces Oxidative Stress Damages}

To better understand the role of the ER gene at a cellular level with regards to thermos-tolerance, various biochemical assays were carried out during the course of this study (Figure 4).
No obvious differences in ion leakage were observed at normal growth temperatures between the transgenic genotypes and the $E V$ controls. The electrolyte efflux started increasing at $24 \mathrm{~h}$ posttreatment in the $E V$ controls. The ion efflux increased by $1.15,1.5$ and 2.7 fold at 24,48 , and $72 \mathrm{~h}$ in the $E V$ controls, respectively. On the other hand, the transgenic plants showed only slight changes (1.1-1.7 fold) at the end of $72 \mathrm{~h}$ (Figure 4A). Similarly, no apparent differences were observed in lipid peroxidation and $\mathrm{H}_{2} \mathrm{O}_{2}$ efflux between untreated transgenic and the $E V$ controls. High temperatures caused a rise in lipid peroxidation and rates of $18 \%$ in the $E V$ controls and $0.086 \%(H+E 58)$ to $8 \%(E R 118)$ in the transgenic genotypes (Figure 4B). After $72 \mathrm{~h}$, the level of $\mathrm{H}_{2} \mathrm{O}_{2}$ was higher in $E V$ controls as compared to the transgenic genotypes (Figure 4C). After $48 \mathrm{~h}$ of the heat treatment, DAB and NBT leaf stains were more pronounced in the $E V$ controls than the transgenic lines, indicating higher accumulations of $\mathrm{H}_{2} \mathrm{O}_{2}$ and $\mathrm{O}_{2}{ }^{-}$, respectively (Figure 4D). Furthermore, the total protein content was significantly reduced in the $E V$ controls as result of the $48 \mathrm{~h}$ long heat stress as compared to the transgenics (Figure 4E). Superoxide dismutase activity was noticeable in the $E V$ controls after the $48 \mathrm{~h}$ heat stress treatment as expected. Of interest, we could not measure any marked differences between plants grown under normal and the heat stress condition for the ER118 and ER122 lines.

\section{Field Trial Plant Growth Performance}

The ER overexpressing Pinellia plants showed a promising heat tolerance under fully controlled growth chamber conditions. To validate this observation, the plantlets were transferred to an open natural field and monitored for field growth performances. Meanwhile, plant growth was monitored also as part of a longterm heat treatment $\left(35^{\circ} \mathrm{C}, 90\right.$-day) (Figures $\left.\mathbf{2 F}-\mathbf{H}\right)$. The daily maximum temperatures range from 16 to $29^{\circ} \mathrm{C}$ in spring and $29-37^{\circ} \mathrm{C}$ in summer. In spring, no obvious growth differences were noticed between the transgenic and the $E V$ controls (Figures 5A,C and Supplementary Table S5), but notable traits differences were observed in the summer season between the transgenic genotypes and the $E V$ controls (Figures 5B,D-F). During the hottest days in summer, the transgenics grew faster than the $E V$ controls. The $E V$ controls were unable to sustain their normal growth and development and their leaves became smaller. We also noticed more indicators of stress such as leaf rolling, drying and abscission (Supplementary Figure S3). Poor root development for the $E V$ controls was obvious whereas the transgenics maintained normal growth and development, generating high biomass values.

The results indicated that no remarkable survival rate differences were observed between the transgenic and the $E V$ controls in spring as almost all the transgenic and the $E V$ controls survived well (Figures 6A-D). However, the survival rate of the $E V$ group was drastically reduced during summer. It is important to point out that the data we obtained did not show any significant growth differences among the transgenic genotypes both in the summer and during spring seasons. The results revealed that both the fresh and the dry tuber weighs were significantly $(P<0.05)$ higher for the transgenic genotypes as compared to the EV controls. Only the line ER118 was similar in 


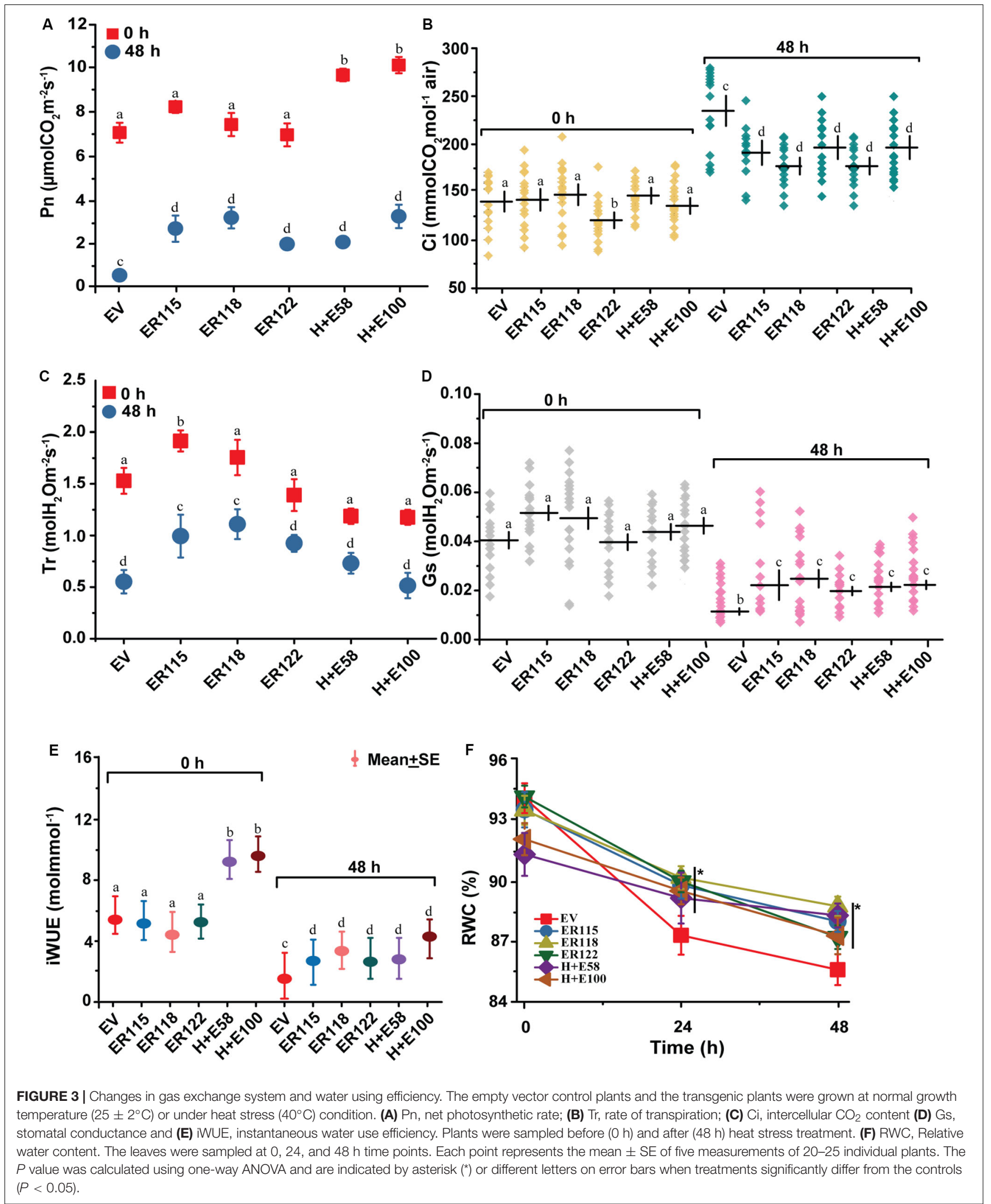




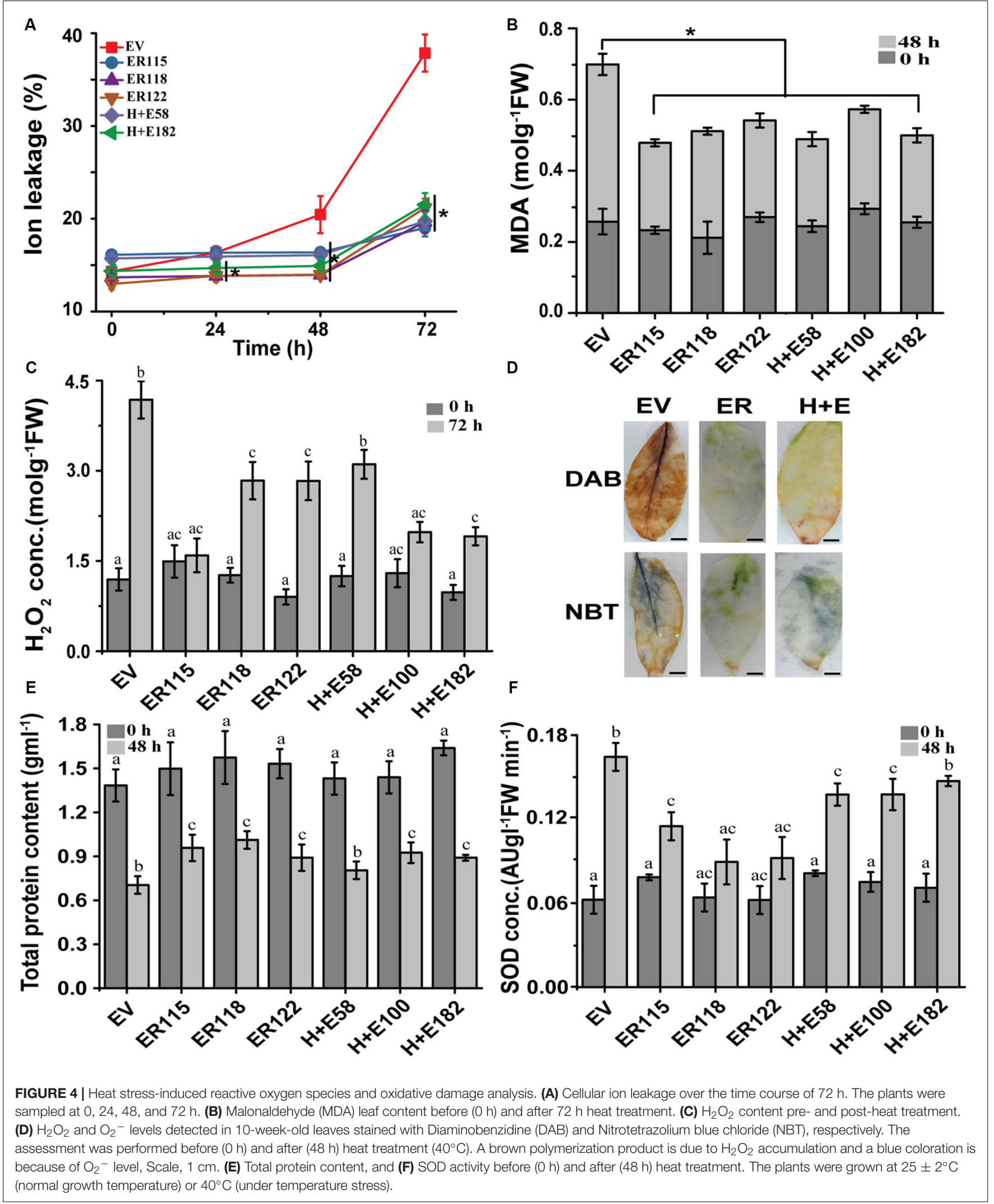



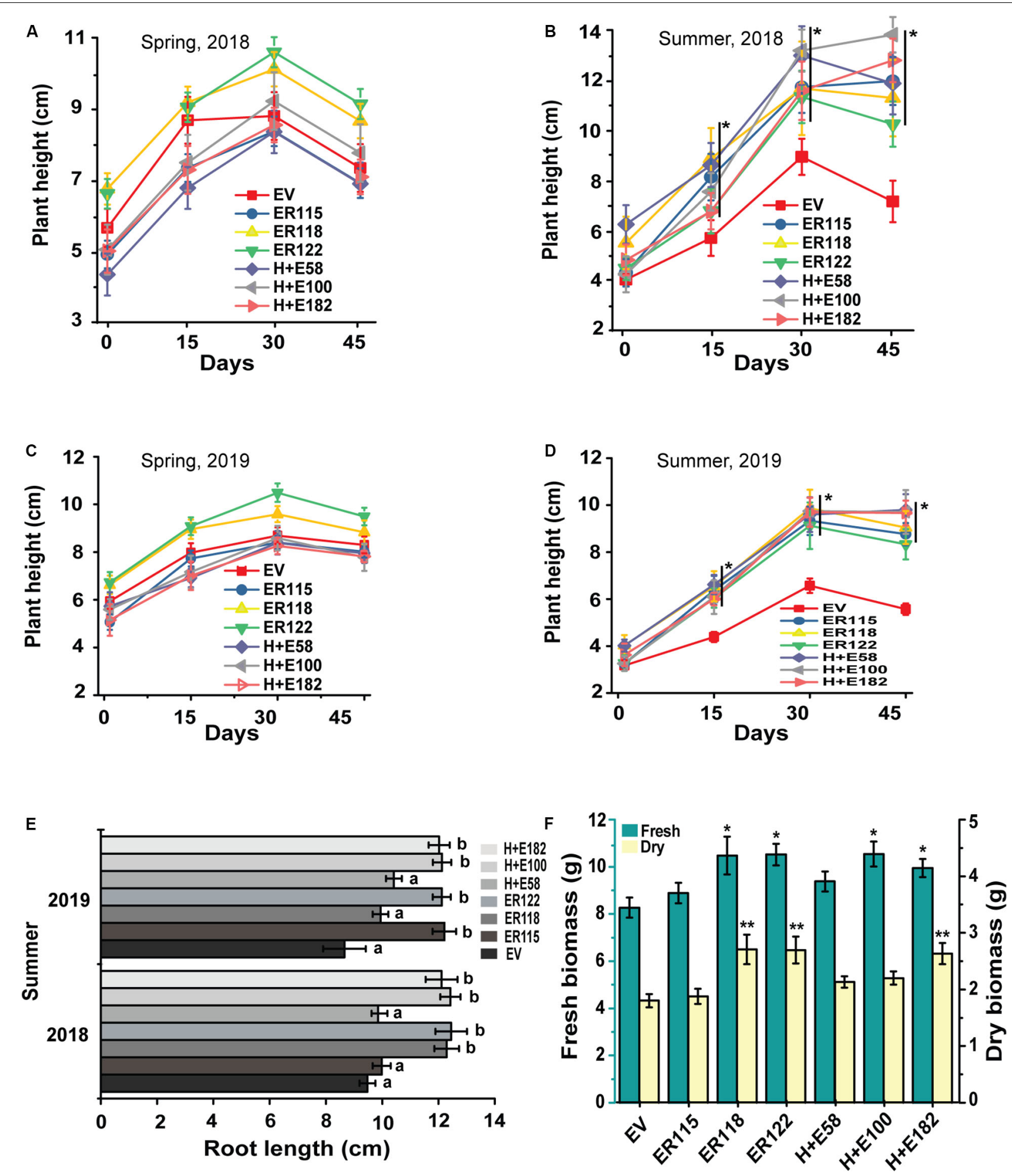

FIGURE 5 | ER improves the growth of $P$. ternata seedlings during the summer heat wave in open natural field. Plant height: (A) Spring-2018, (B) summer-2018, (C) spring-2019 and (D) summer-2019, (E) Root length, (F) Seedling fresh and dry biomass. The root length and plant biomass were recorded after 45-days. The $P$ value was calculated using one-way ANOVA and are indicated by asterisk $\left(^{*}\right)$ or different letters on error bars when the treatments are significantly different from the empty vector controls $(P<0.05)$. 

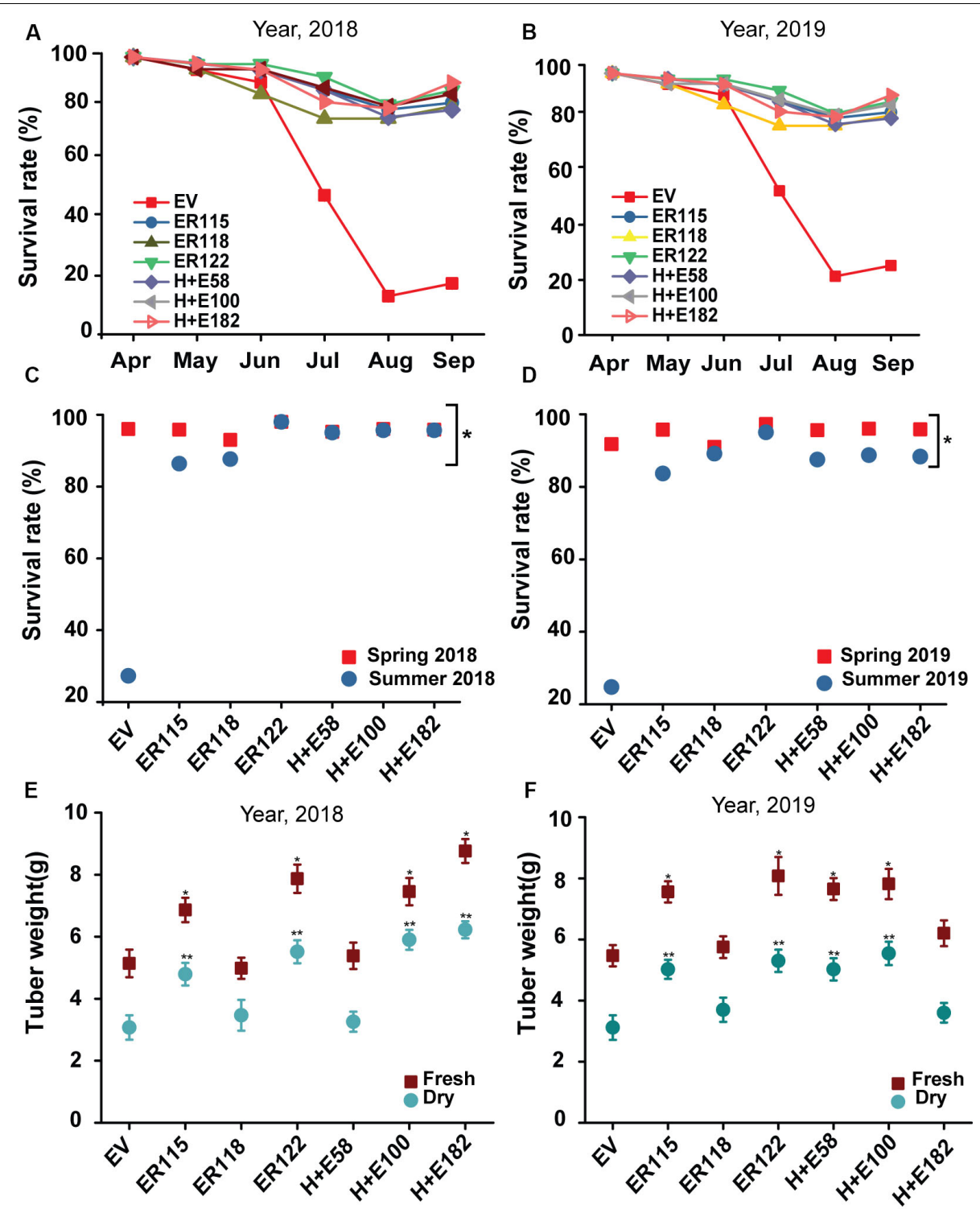

G

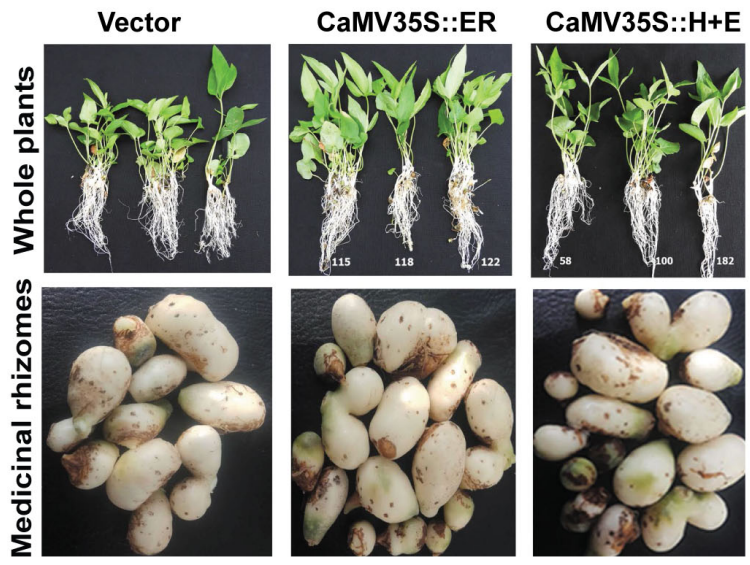

FIGURE 6 | ER breaks the summer dormancy and improves tuber biomass. The plant survival rates were monitored in year (A) 2018 and (B) 2019 . The proportions of survived plants were also computed at the end of spring and summer seasons (C) 2018 and (D) 2019. Analysis of tuber weight in (E) 2018 and (F) 2019, 25-30 plants each. The tuber weights were recorded per pot. (G) Phenotype of 16-week-old $P$. terneta seedlings that grown the last 6 weeks in open natural field (the first upper panels) and tuber morphology harvested at the end of summer (the second lower panels), scale $1 \mathrm{~cm}$. 


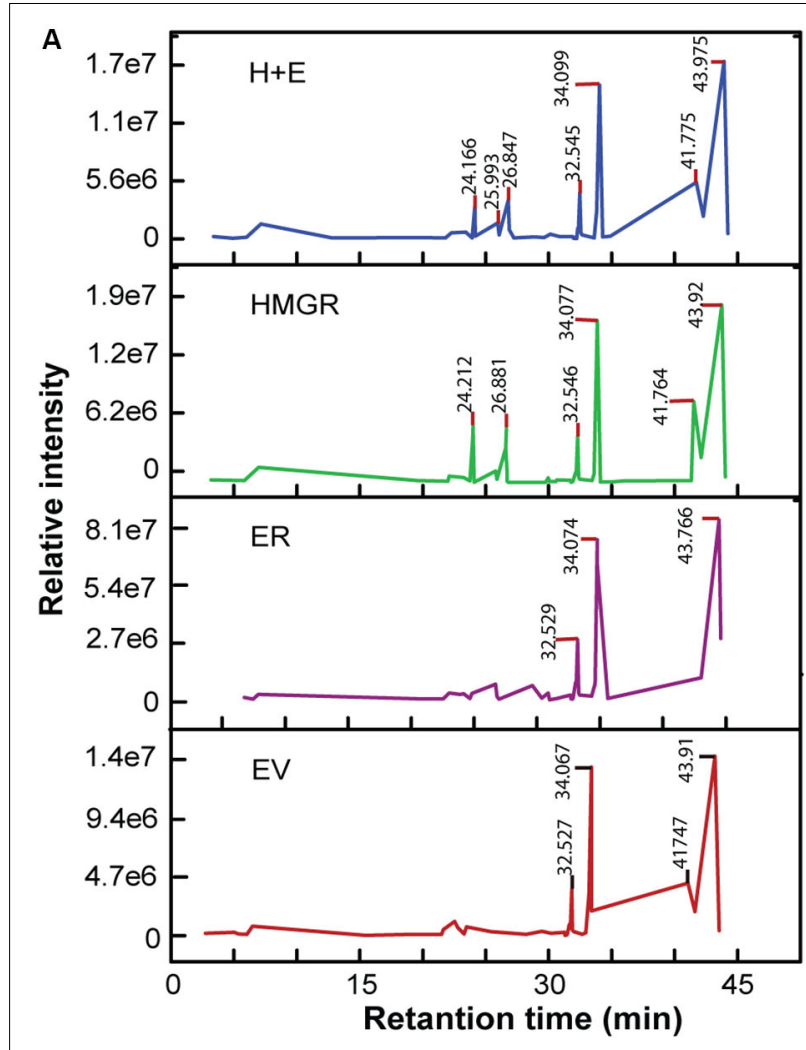

B $\quad 2.7 e 7$ Desulphosinigrin

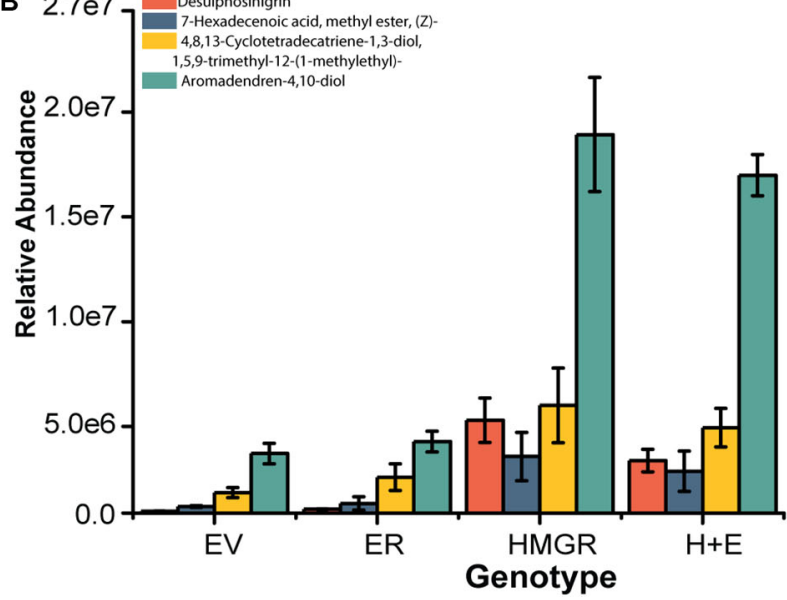

FIGURE 7|HMGR enhances the metabolites content of $P$. ternata. The methanolic tuber extracts were used for metabolite analysis. (A) Total ion chromatograms and (B) the relative abundance of differently detected compounds in the transgenic lines. The intensity of peak is the mean of three HMGR overexpressing genotypes or the mean of three control plants.

its growth measurements to the $E V$ controls both in the growth chamber and in open isolated field trials.

\section{HMGR Overexpression Changes the Metabolites Content of $P$. ternata}

The HMGR is a key gene in the biosynthesis of terpenoids. Twenty transgenic plants of each genetic construct and
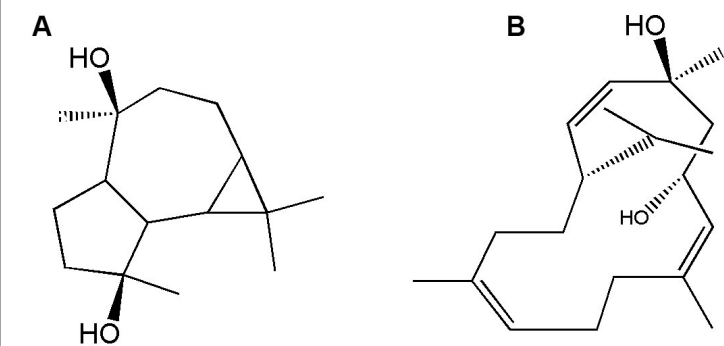<smiles>C=CCC(=NO)SC1OC(CO)C(O)C(O)C1O</smiles><smiles>[C+]CCCCCCC/C=C/CCCCC(=O)OC</smiles>

FIGURE $\mathbf{8}$ | Chemical structure of differently produced compounds in the HMGR overexpressing transgenic $P$. ternata tuber extracts.

(A) Aromadendrene-4,10-diol; (B) 4,8,13-Cyclotetradecatriene- 1,3-diol, 1,5,9-trimethyl-12-(1-methylethyl)-; (C) Desulphosinigrin and (D) 7-Hexadecenoic acid, methyl ester, (Z)-.

qRT-PCR gene expression analysis confirmed the transgenic transformation status of regenerants (Figures 2A,C). The preliminary screening and selection data are indicated in the Supplementary Material (Supplementary Figure S2). The EV and the ER plants were used as controls in assessing the roles of $H M G R-\mathrm{OE}$ in altering the metabolite contents. The relative abundances of the differently detected compounds are shown in Supplementary Table S6. Generally, similar compounds were detected in both the controls and the transgenic plants, but some of the compounds occurred at higher concentrations in some of the lines such as aromadendrene-4, 10-diol; 4, 8, 13-cyclotetradecatriene-1, 3-diol, 1, 5, 9-trimethyl-12-(1methylethyl)-; desulphosinigrin and 7-hexadecenoic acid, methyl ester. The first two compounds belong to terpenoids, whereas the latter two compounds are an alkaloid and a fatty acid ester, respectively. These compounds were differently produced in the $H M G R$ transgenic genotypes (Figure 7B). Figure 8 shows the chemical structure of compounds that were differently detected in the transgenic lines.

\section{DISCUSSION}

\section{ER Overexpression Removes the Summer Dormancy of $P$. ternata}

Heat stress has detrimental impacts on plant growth, development, and yield worldwide (Long and Ort, 2010). Plants have evolved various mechanisms to cope with various stressing conditions (Kotak et al., 2007; Shen et al., 2015). 
P. ternata adapts to a summer dormancy status as part of its natural regime to cope with climatic conditions when growing in hot environments. To break the summer dormancy of $P$. ternata, the $E R$ gene was successfully overexpressed, producing a batch of transgenic lines (Figures 2B,C and Supplementary Figures S1B-D). The ER gene has been characterized as an important heat and drought stress regulator in plants. It controls plant growth from the early stages, throughout the developmental processes to the maturity of the plants in Arabidopsis (Qu et al., 2017), tomato and rice (Shen et al., 2015) and poplar (Xing et al., 2011). Similarly, ER-OE P. ternata lines showed a significantly improved plant growth performance, heat stress survival and recovery rates as compared to the $E V$ controls in this study.

It was hypothesized that ER-OE could enhance $P$. ternata thermo-tolerance, allowing the plant to cope under such conditions (Figures 1A,B). From a plant physiological viewpoint, we have shown that the transgenic genotypes had markedly higher chlorophyll content (Figure 2D) and better carbon assimilating capacity (Figure $\mathbf{3 A}$ ) as compared to the $E V$ controls. The CaMV35S:ER and CaMV35S:HMGR + ER leaves were greener and healthier than the $E V$ controls confirming normal photosynthesis in the transgenic genotypes. Temperature stress affects the physiological and biochemical response mechanisms of a plant (Djanaguiraman et al., 2010; Hasanuzzaman et al., 2013). Although the net photosynthetic rate and chlorophyll concentrations decreased during the heat treatment, these effects were more pronounced in the $E V$ controls than the transgenic lines. This possibly indicates the extent of chlorophyll degradation and/or oxidative damage of the Photosystem II (PSII) in the EV controls. Heat stress primarily causes injury to the chlorophyll pigments and eventually leads to inhibition of the photosystems and enzyme activities (Hasanuzzaman et al., 2013). Higher net photosynthetic rates were recorded for the $H+E 58$ and $H+E 100$ lines and transpiration rate for the ER115 and ER118 genotypes at normal growth temperature. Such observed minor differences among transgenic lines might be attributed to the somaclonal variations that are due to in vitro culture or pre-existed in the explants. The gas exchange data suggest that carbon fixation was more efficient in the transgenic lines than the EV controls during heat stress (Figures 3C,D). Such data are consistent with other reports (Hector et al., 2012; Shen et al., 2015).

Since $E R$ has been characterized as a major player in regulating transpiration efficiency (Masle et al., 2005), many studies have demonstrated its role in enhancing instantaneous water-use efficiency under different environmental stresses (Linzhou et al., 2013; Shen et al., 2015). It is interesting to note that the instantaneous water-use efficiency was, however, enhanced in all the transgenic genotypes, reflecting their higher carbon fixation efficiency (Figure 3E). The relative water content was also significantly higher for the transgenic genotypes than the $E V$ controls (Figure 3F). The ability of plants to manage their water content effectively and control their transpiration rate is regarded as a good indicator for heat stress resistance when they are under stress (Xu et al., 2014).

Cell injury associated with plasma membrane disruptions and/or cell wall ruptures are the typical plant cell heat stress indicators, and electrolyte leakage, lipid peroxidation and/or ROS accumulation are exacerbated as a result of stress in plants (Djanaguiraman et al., 2010; Song et al., 2012; Shen et al., 2015). The ER-OE transgenic lines were better able to tolerate heat stress as shown by the lower levels of biochemical stress indicators (Figures 4A-D). The accumulation of $\mathrm{H}_{2} \mathrm{O}_{2}$ and $\mathrm{O}_{2}{ }^{-}$ was greater in the $E V$ controls possibly leading to effects that impaired their growth. The ERECTA is thought to maintain the integrity of the plasma membrane during heat stress, and also has a role in scavenging the ROS that affect the structural integrity of the plasma membrane. There is still much that is unknown with regards to the cellular and molecular heat stress tolerance mechanisms linked to ER regulation. Stress responses in plants are highly complex and SOD is involved in the antioxidant defense system, and hence the elevated levels in those plants that are more susceptible to ROS production during heat stress. The lower SOD activity in the transgenics suggested better thermal tolerance as opposed to the $E V$ controls that had much higher levels.

Field trials were important in validating the experimental differences that were observed under controlled growth conditions. In the present study, the ER-OE P. ternata had a better heat stress endurance and growth performance during field trials. The ER transgenic plants exhibited distinctive phenotypes as compared to the $E V$ controls as they grew more rapidly and had longer roots. Biomass production is also another important growth parameter that is often severely affected when plants grow under stress environments (Figures $\mathbf{5 A - F}$ ) and those that are able to cope with the stress show better growth performance and this boosted biomass is often linked to rate of carbon assimilation (Linzhou et al., 2013; Shen et al., 2015). In this study, 84\%-95\% of the transgenic Pinellia plants survived the summer heat wave, exhibiting a higher tuber biomass as compared to the $E V$ controls with a survival rate of $25 \%$ (Figures $6 \mathrm{E}-\mathrm{G}$ ). This effect may not necessarily be unique to Pinellia as in a previous study of Shen et al. (2015), ER overexpressed in tomato and rice led to better adaption to the high summer temperature in field tests at Wuhan and Shanghai. In Mediterranean climates, the summer dormancy that is associated with plants endemic to the region is said to be an ecological advantage that confers higher levels of survival under severe drought stress (Balachowski et al., 2016) and the water content is possibly a determining factor that regulates summer dormancy (Shane et al., 2010). In central and southern China, where $P$. ternata shows summer dormancy, drought is less likely to be an evolutionary selection factor as Wuhan, as an example, receives average precipitation that exceeds $1,315 \mathrm{~mm}$ per year. It is thus more likely that temperature might be the major driving force controlling the summer dormancy of $P$. ternata. Our findings suggest that a single heat tolerance 
heterologous gene can break the summer dormancy patterns of this species. Little has been done to understand the underlying mechanisms that control summer dormancy and practices to break dormancy in plants appear to species and cultivar specific. In this study we show that heat-stress imposed dormancy is negated in ER-OE P. ternata (Figure 4) and this is a new mechanism that has practical applications.

\section{HMGR Alters the Metabolite Content of P. ternata}

The HMGR has been studied as a key and rate-limiting enzyme in the biosynthesis of a diverse spectrum of specialized metabolites in plants, and some examples include A. thaliana and Panax ginseng (Kim et al., 2014), Salvia miltiorrhiza (Dai et al., 2011) and Gossypium hirsutem (Loguercio et al., 1999). It provides a suite of precursor molecules that ultimately lead to synthesis of a wide range of terpenoids (Dai et al., 2011; Bansal et al., 2018). For instance, the HMGR overexpression or down-regulation leads to the apparent increase/decrease of the down-stream tanshinone and squalene content in transgenic Salvia roots (Dai et al., 2011). In the present study, P. ternata, overexpressing HMGR enhanced the content of aromadendrene-4, 10-diol (sesqueterpene) and 4, 8, 13-cyclotetradecatriene-1, 3-diol, 1, 5, 9-trimethyl-12(1-methylethyl) (diterpene) in transgenic plants. This finding is in line with the work of others that conclude HMGROE improves the content of sesquiterpenes and diterpenes in plants (Tholl, 2006; Dai et al., 2011; Kim et al., 2014). These compounds have been previously reported from P. ternata plant (Wang et al., 1995; Fu, 2005; Iwasa et al., 2014). Two non-terpenoid compounds that were identified as desulphosinigrin and 7-hexadecenoic acid methyl ester (Zhang et al., 2002; Wang et al., 2008) were also enhanced in transgenic genotypes.

Up-regulation of the rate-limiting enzymes are used to enhance the secondary metabolite production in plants and these metabolites are well known in assisting plants with coping with abiotic and biotic factors (Mahmoud and Croteau, 2002; Tholl, 2006; Dai et al., 2011). In our current study, however, the HMGR-OE transgenic plants had similar growth and development phenotypes to the control plants when treated with a heat stress. It is quite likely that those metabolites that were enhanced in their production do not necessarily have significant roles in combating heat stress. According to Wang et al. (2018), HMGR functions more efficiently at $28^{\circ} \mathrm{C}$ and radically declines when temperature rise to $40^{\circ} \mathrm{C}$ plus it is more active in young growing roots tip and apical buds than the matured plant tissues, showing a spatial regulation in its function. Although this is speculative, this might possibly be the reason for early senescence of older leaves and susceptibility of the HMGR transgenic plants to heat stress. Our initial idea assumed that HMGR-OE improves both plant tolerance to heat and accumulation of specialized metabolites and we could only confirm the latter in the HMGR transgenic lines (Figures 7, 8).

In conclusion, the ER-OE alleviates damaging effects caused by high temperature stress, imparting the thermo-tolerance in
P. ternata. The mechanisms of how the ER gene controls cellular and molecular heat resistance is still unclear, needing more indepth investigations to better understand how it governs heat stress shown here. Our study could not conclude on HMGR-OE regulated heat tolerance in $P$. ternata but the effect of this gene at the metabolite level was confirmed. This study has conclusively contributed toward generating heat-stress tolerant new Pinellia varieties with enhanced metabolite content. The Pinellia summer dormancy, which is intrinsic to the growth cycle of the species, can be altered through the introduction of a single heterologous gene. This novel finding provides a new genetic engineering strategy in $P$. ternata for future market needs.

\section{DATA AVAILABILITY STATEMENT}

The raw data supporting the conclusions of this article will be made available by the authors, without undue reservation, to any qualified researcher.

\section{AUTHOR CONTRIBUTIONS}

SJ, ZG, WC, and XH conceived and designed the experiments. SJ, ZG, and HY performed the experiments. SJ, XL, SH, and $\mathrm{XH}$ analyzed data. SJ, HY, and WC contributed in metabolite analysis. SJ, NM, XL, and XH wrote the manuscript. All authors checked the manuscript.

\section{FUNDING}

The research was financed by National Science and Technology Fundamental Resources Investigation Program of China (No. 2018FY100704) awarded to XL. This research was also supported by National Key R\&D Program of China (No. 2017YFD0501500), "China National Key Project on High-level foreign experts" by State Administration of Foreign Experts Affairs P.R. China (No. G20199917994) and the Fundamental Research Funds for the Central Universities program (Nos. 2662017PY110 and 2662015CFA091) all awarded to XH. The work of NM was supported through the National Research Foundation of South Africa (IFR190205413820).

\section{ACKNOWLEDGMENTS}

We are thankful to Prof. He Zuhua and Dr. Zhang Yansheng for their generous gift of $p C A M B I A 1301$ and PESC-HIS-mvaA vectors, respectively. Mrs. Bernadette Van Heerden is thanked for proof-reading this manuscript and language editing.

\section{SUPPLEMENTARY MATERIAL}

The Supplementary Material for this article can be found online at: https://www.frontiersin.org/articles/10.3389/fpls.2020.00780/ full\#supplementary-material 


\section{REFERENCES}

Alexieva, V., Sergiev, I., Mapelli, S., and Karanov, E. (2001). The effect of drought and ultraviolet radiation on growth and stress markers in pea and wheat. PlantCell Environ. 24, 1337-1344. doi: 10.1046/j.1365-3040.2001.00778.x

Balachowski, J. A., Bristiel, P. M., and Volaire, F. A. (2016). Summer dormancy, drought survival and functional resource acquisition strategies in California perennial grasses. Ann. Bot. 118, 357-368. doi: 10.1093/aob/mcw109

Bansal, S., Narnoliya, L. K., Mishra, B., Chandra, M., Yadav, R. K., and Sangwan, N. S. (2018). HMG-CoA reductase from Camphor Tulsi (Ocimum kilimandscharicum) regulated MVA dependent biosynthesis of diverse terpenoids in homologous and heterologous plant systems. Sci. Rep. 8:3547. doi: $10.1038 / s 41598-017-17153-\mathrm{z}$

Beauchamp, C., and Fridovich, I. (1971). Superoxide dismutases: improved assays and an assay predictable to acrylamide gels. Ann. Clin. Biochem. 44, 276-287. doi: 10.1016/0003-2697(71)90370-8

Dai, Z., Cu, I. G., Zhou, S.-F., Zhang, X., and Huang, L. (2011). Cloning and characterization of a novel 3-hydroxy-3-methylglutaryl coenzyme A reductase gene from Salvia miltiorrhiza involved in diterpenoid tanshinone accumulation. J. Plant Physiol. 168, 148-157. doi: 10.1016/j.jplph.2010.06.008

Djanaguiraman, M., Prasad, P. V., and Seppanen, M. (2010). Selenium protects sorghum leaves from oxidative damage under high temperature stress by enhancing antioxidant defense system. Plant Physiol. Biochem. 48, 999-1007. doi: 10.1016/j.plaphy.2010.09.009

Froger, A., and Hall, J. E. (2007). Transformation of plasmid DNA into E. coli using the heat shock method. J. Vis. Exp. 2007:253. doi: 10.3791/253

$\mathrm{Fu}, \mathrm{C}$. (2005). The first prescription for the treatment of insomnia-the applications of banxia shumi decoction. Jiangxi J. Tradit. Chin. Med. 36, 56-57.

Gillespie, L. M., and Volaire, F. A. (2017). Are winter and summer dormancy symmetrical seasonal adaptive strategies? The case of temperate herbaceous perennials. Ann. Bot. 119, 311-323. doi: 10.1093/aob/mcw264

Hasanuzzaman, M., Nahar, K., Alam, M. M., Roychowdhury, R., and Fujita, M. (2013). Physiological, biochemical, and molecular mechanisms of heat stress tolerance in plants. Int. J. Mol. Sci. 14, 9643-9684. doi: 10.3390/ijms 14059643

Hector, V., Anne-Claire Morine, D., Shpak, E., and Khodakovskaya, M. V. (2012). Modification of tomato growth by expression of truncated ERECTA protein from Arabidopsis thaliana. J. Exp. Bot. 68, 6493-6504. doi: 10.1093/jxb/ers305

Hongying, W., Shen, W., Hongda, L., Zhang, L., and Huang, S. (2015). Study on the anti-motion sickness action of volatile oil constituents in Pinellia ternate. Biomed. Res. 26, 230-234.

Hu, S. (1989). Textual research of Chinese materia medica of Pinellia ternata. Chin J. Chin. Mater. Med. 149, 6-9.

Iwasa, M., Iwasaki, T., Ono, T., and Miyazawa, M. (2014). Chemical composition and major odor-active compounds of essential oil from PINELLIA TUBER (dried rhizome of Pinellia ternata) as crude drug. J. Oleo Sci. 63, 127-135. doi: 10.5650/jos.ess 13092

Jin, B., Jiang, F., Yu, M., Chen, N., and Ding, Z. (2009). Agrobacterium tumefaciens mediated Chitinase and $\beta$-1,3-glucanase gene transformation for Pinellia ternata. Chin. J. Chin. Materi. Med. 34, 1765-1767.

Kim, Y. J., Lee, O. R., Oh, J. Y., Jang, M.-G., and Yang, D.-C. (2014). Functional analysis of 3-Hydroxy-3-Methylglutaryl coenzyme a reductase encoding genes in triterpene saponin-producing ginseng. Plant Physiol. 165, 373-387. doi: 10. 1104/pp.113.222596

Kotak, S., Larkindale, J., Lee, U., von Koskull-Döring, P., Vierling, E., and Scharf, K.-D. (2007). Complexity of the heat stress response in plants. Curr. Opin. Plant Biol. 10, 310-316. doi: 10.1016/j.pbi.2007.04.011

Krohn, R. I. (2001). The colorimetric detection and quantitation of total protein. Curr. Protoc. Cell. Biol. 15, 1-28.

Kumar, D., Yusuf, M., Singh, P., Sardar, M., and Sarin, N. (2014). Histochemical detection of superoxide and $\mathrm{H} 2 \mathrm{O} 2$ accumulation in Brassica juncea seedlings. Bio Protocol 4:e1108. doi: 10.21769/bioprotoc. 1108

Lee, P. N. H., Lee, W., Kim, E. H., Jin, Y. H., Seo, E. K., and Honhg, J. (2016). Comprehensive chemical profiling of Pinellia species tuber and processed Pinellia tuber by gas chromatography - mass spectrometry and liquid chromatography - atmospheric pressure chemical ionization - tandem mass spectrometry. J. Chromatogr. A. 4, 164-177. doi: 10.1016/j.chroma.2016.10.033

Linzhou, H., Huang, T., Yasir, A., Phillips, A. L., and Hu, Y.-G. (2013). Isolation and characterization of ERECTA genes and their expression patterns in common wheat (Triticum aestivum L.). J. Crop Sci. 7, 381-390.
Livak, S. T. (2001). Analysis of relative gene expression data using real-time quantitative PCR and the 2(-Delta Delta C(T)) Method. Methods 25, 402-408. doi: 10.1006/meth.2001.1262

Loguercio, L. L., Scott, H. C., Trolinder, N. L., and Wilkins, T. A. (1999). Hmg-coA reductase gene family in cotton (Gossypium hirsutum L.): unique structural features and differential expression of hmg2 potentially associated with synthesis of specific isoprenoids in developing embryos. Plant Cell Physiol. 40, 750-761. doi: 10.1093/oxfordjournals.pcp.a029602

Long, S. P., and Ort, D. R. (2010). More than taking the heat: crops and global chang. Curr. Opin. Plant Biol. 13, 241-248.

Ma, X.-J., Li, X.-W., Du, J., Xue, M., Li, T., and Luo, Y.-C. (2006). ). Study on marking method for germplasm evaluation of Pinellia ternata. Chin. J. Chin. Mater. Med. 31, 975-977.

Mahmoud, S. S., and Croteau, R. B. (2002). Strategies for transgenic manipulation of monoterpene biosynthesis in plants. Trends Plant Sci. 7, 366-373. doi: 10. 1016/S1360-1385(02)02303-8

Masle, J., Gilmore, S. R., and Farquhar, G. D. (2005). The ERECTA gene regulates plant transpiration efficiency in Arabidopsis. Nature 436, 866-870. doi: 10.1038/ nature 03835

Murashige, T., and Skoog, F. (1962). A revised medium for rapid growth and bio assays with tobacco tissue cultures. Physiol. Plant. 15, 473-497. doi: 10.1111/j. 1399-3054.1962.tb08052.x

Qu, X., Zhao, Z., and Tian, Z. (2017). ERECTA regulates cell elongation by activating auxin biosynthesis in Arabidopsis thaliana. Front. Plant Sci. 8:1688. doi: $10.3389 /$ fpls.2017.01688

Shane, M. W., McCully, M. E., Canny, M. J., Pate, J. S., Huang, C., and Ngo, H. L. (2010). Seasonal water relations of Lyginia barbata (Southern rush) in relation to root xylem development and summer dormancy of root apices. New Phytol. 185, 1025-1037. doi: 10.1111/j.1469-8137.2009.03143.x

Shen, H., Zhong, X., Zhao, F., Wang, Y., Yan, B., Li, Q., et al. (2015). Overexpression of receptor-like kinase ERECTA improves thermotolerance in rice and tomato. Nat. Biotechnol. 33, 996-1006. doi: 10.1038/nbt.3321

Shiu, S.-H., Karlowski, W. M., Pan, R., Tzeng, Y.-H., Mayer, K. F. X., and Li, W.-H. (2004). Comparative Analysis of the receptor-like kinase family in Arabidopsis and rice. Plant Cell 16, 1220-1234. doi: 10.1105/tpc.020834

Shpak, E., Berthiaume, C., Hill, E., and Torii, K. U. (2004). Synergistic interaction of three ERECTA-family receptor-like kinases controls Arabidopsis organ growth and flower development by promoting cell proliferation. Development 13, 149-151.

Shpak, E. D. (2013). Diverse roles of ERECTA family genes in plant development. J. Integr. Plant Biol. 55, 1238-1250. doi: 10.1111/jipb.12108

Song, W. Y., Sun, C., Wang, Y., Peng, Y., and He, C. (2012). Effects of pyrene on antioxidant systems and lipid peroxidation level in mangrove plants, Bruguiera gymnorrhiza. Ecotoxicology 21, 1625-1632. doi: 10.1007/s10646-012-0945-9

Tang, J., Chen, M., and Liu, W. (2008). Obtaining of anti-glyphosate Pinelliaternata and establishment of transformation system using glyphosate as selectable marker. Tradit. Herbal Drugs 39:585.

Tholl, D. (2006). Terpene synthases and the regulation, diversity and biological roles of terpene metabolism. Curr. Opin. Plant Biol. 9, 297-304. doi: 10.1016/j. pbi.2006.03.014

Wang, J. Y., Wang, X.-D., Ma, Y.-D., Fu, L.-C., Zhou, H.-H., Wand, B., et al. (2018). Physiological and ecological responses to drought and heat stresses in Osmanthus fragrans 'Boyejingui'. Chin. J. Plant Ecol. 42, 681-691. doi: 10.17521/ cjpe. 2018.0017

Wang, R., Ni, J., and Ma, R. (1995). Volatile oils of Pinellia ternata. Chin. Pharm. J. $30,457-459$.

Wang, X. S., Wu, Y. F., Ma, J. Y., and Qilu, Q. L. S. (2008). Study on chemical components and pharmacological activities of Pinellia ternata. Pharm. Aff. 27, 101-103.

Wu, X.-Y., Zhao, J.-L., Zhang, M., Li, F., Zhao, T., and Yang, L.-Q. (2011). Sedative, hypnotic and anticonvulsant activities of the ethanol fraction from rhizoma pinelliae praeparatum. J. Ethnopharmacol. 135, 325-329. doi: 10.1016/j.jep. 2011.03.016

Xing, H., Peng, G., Xin, L., and Wei, L. (2011). PdERECTA, a leucine-rich repeat receptor-like kinase of poplar, confers enhanced water use efficiency in Arabidopsis. Planta 234, 229-241. doi: 10.1007/s00425-011-1389-9

Xu, Q., Xu, X., Shi, Y., Xu, J., and Huang, B. (2014). Transgenic tobacco plants overexpressing a grass PpEXP1 gene exhibit enhanced tolerance to heat stress. PLoS One 9:e100792. doi: 10.1371/journal.pone.0100792 
Xu, T., Zhang, L., Sun, X., and Tang, K. (2005). Efficient in vitro plant regeneration of Pinellia ternata (Thunb) Breit. Acta Biol. Crac. Ser. Bot. 2, 27-32.

Yang, Y., Li, R., and Qi, M. (2000). In vivo analysis of plant promoters and transcription factors by Agroinfiltration of tobacco leaves. Plant J. 22, 543-551. doi: 10.1046/j.1365-313x.2000.00760.x

Zang, X., Geng, X., Wang, F., Liu, Z., Zhang, L., Zhao, Y., et al. (2017). Overexpression of wheat ferritin gene TaFER-5B enhances tolerance to heat stress and other abiotic stresses associated with the ROS scavenging. BMC Plant Biol. 17:14. doi: 10.1186/s12870-016-0958-2

Zhang, J. Y., Guo, Q. S., and Zheng, D. S. (2013). Genetic diversity analysis of Pinellia ternata based on SRAP and TRAP markers. Biochem. Syst. Ecol. 50, 258-265. doi: $10.1016 /$ j.bse.2013.03.052

Zhang, K. W., Wu, H., and Wu, L. L. (2002). A study on component of aliphatic acid in Rhizoma Pinelliae ternata Praeparata. J. Nanjing TCM Univ.18, 291-302.

Zhu, Y., Zhu, G., Guo, Q., Zhu, Z., Wang, C., and Liu, Z. (2018). Cloning and expression of a new cytoplasmic small heat shock protein gene from
Pinellia ternata. Acta Physiol. Plant. 40, 1-44. doi: 10.1007/s11738-0182605-Z

Zuo, Z., Fan, H., Wang, X., Zhou, W., and Li, L. (2012). Purification and characterization of a novel plant lectin from Pinellia ternata with antineoplastic activity. SpringerPlus 1:13. doi: 10.1186/2193-1801-1-13

Conflict of Interest: The authors declare that the research was conducted in the absence of any commercial or financial relationships that could be construed as a potential conflict of interest.

Copyright (c) 2020 Juneidi, Gao, Yin, Makunga, Chen, Hu, Li and Hu. This is an open-access article distributed under the terms of the Creative Commons Attribution License (CC BY). The use, distribution or reproduction in other forums is permitted, provided the original author(s) and the copyright owner(s) are credited and that the original publication in this journal is cited, in accordance with accepted academic practice. No use, distribution or reproduction is permitted which does not comply with these terms. 